\title{
Análisis del contenido de cuatro estudios de religiosidad popular en Chile
}

\author{
Marcelo Armold, Teresa Prado y \\ Vivian Saidel
}

\section{Características de las investigaciones}

Los estudios nacionales -específicamente de la zona central- realizados en torno al tema de la religiosidad popular chilena pueden ser clasificados en tres grandes categorías: folclóricos, históricos y sociológicos, entendida esta clasificación en un sentido amplio. Sin pretender abarcar todos los estudios publicados, procederemos, en esta ocasión, a analizar el contenido de algunos que decididamente se presentan como las fuentes más consultadas por los investigadores interesados en este tema.

Si bien ningún texto abarca la totalidad de la información que sobre religiosidad popular puede obtenerse, es sin duda, la publicación del investigador Oreste Plath la que más se acerca a ese objetivo, al pretender exponer de una manera extensiva, utilizando un criterio de tipo geográfico, las manifestaciones rituales más importantes de la religiosidad popular chilena.

Similar perspectiva puede ser detectada en publicaciones más recientes (URIBE, PRADO). En éstas, si bien se gana en profundidad y riqueza de detalles, en relación con la obra de Plath, se pierde la visión de conjunto necesaria para la apreciación del fenómeno a nivel nacional.

Los estudios netamente folclóricos, en el sentido de rescate de la tradición popular, son ya bastante numerosos, especialmente aquellos que abordan la religiosidad a partir de sus manifestaciones poéticas. Destaca en este sentido la extensa recopilación realizada por el sacerdote católico Miguel Jordá (1975, 1976). En sus obras se rescata con plenitud la dimensión poético-literaria mediante la cual se manifiesta en gran medida la religiosidad popular campesina. Similar perspectiva ha sido desarrollada en los estudios de Maximiliano Salinas. 
La perspectiva histórica, los análisis del origen y el desenvolvimiento de la religiosidad en Chile, han sido profusamente desarrollados por Gabriel Guarda (1973a, 1973b), Luis E. Silva, Marciano Barrios, entre muchos otros. De sus lecturas se desprende con nitidez que la aplicación mecánica del concepto de sincretismo para estos fenómenos, oculta una compleja trama de factores históricos y culturales de alta complejidad e importancia.

Puede ser reconocido, además, un tipo de investigación adyacente a los intereses del folclorólogo, historiador y muy cercano al sociólogo: se trata de un tipo de investigación que bien pudiéramos llamar aplicada, cuyos mejores exponentes han sido los Rectores y grupos que han trabajado en el Santuario Nacional de Nuestra Señora del Carmen de Maipú. Estos no sólo realizan estudios y jornadas de análisis sino que también promueven y catequizan algunas manifestaciones religioso-populares, en especial las de carácter comunitario. Como es obvio, se trata de investigaciones legítimamente interesadas que surgen bajo el alero de la Iglesia Católica y motivadas con un claro influjo postconciliar (Alliende).

Las orientaciones sociológicas pueden estar representadas por cuatro importantes estudios: el del sociólogo suizo Cristián Lalive, los de Antonio Cruz Pacheco, de Antonio Bentué y los de equipo de la Vicaría Zona Oeste de la Iglesia de Santiago (PArker y otros). En todos ellos se aprecia una gran sistematicidad, orientados por los cánones de una explícita metodología convencional en ciencias sociales y se aplican a contextos socioculturales de carácter marginal, especialmente urbanos.

Dada su importancia procederemos a reseñar de una manera sistemática los estudios sociológicos antes aludidos, para lo cual aplicaremos un análisis de sus contenidos de acuerdo a procedimientos que expondremos a continuación.

\section{Procedimientos para el análisis de Contenido}

Es un lugar común para las ciencias sociales, en particular para la antropología, recurrir con ánimo comparativo a fuentes documentales con el fin de generalizar o apoyar una visión general o contextual del fenómeno que nos preocupa. El presente artículo se dirige precisamente a un cuestionamiento crítico de aquel quehacer y a sugerir nuevas modalidades para el análisis del contenido aplicable a estudios socioculturales.

Sin duda el problema más grande que debe superar el comparativista es el control de la calidad de la información a que recurre. La calidad de la data es esencial puesto que es justamente a partir de ella de donde se generan o se comprueban hipótesis. Es relativamente común que los estudios publicados tengan fallas, productos de errores involuntarios, exageraciones, etc. Estos provocarán fuertes distorsiones en el trabajo comparativo, originándose a partir de ello un interés cada vez mayor por el control de la calidad de la data. En antropología social el ejemplo más claro de estos problemas y del desconcierto 
que origina en otros investigadores que quisieran o necesitan servirse de información ya recogida, es la polémica Redfield-Lewis acerca de la comunidad mexicana de Tepoztlán.

Robert Redfield presentó una imagen de la comunidad de Tepoztlán totalmente opuesta a la de Oscar Lewis. Siendo ambos connotados antropólogos, el asunto generó una ardua y larga discusión. En concreto, mientras Redfield definió a Tepoztlán como una comunidad feliz, amistosa y cooperativa, Lewis la encontró infeliz, inamistosa e individualista. ¿Qué había pasado? Los veinte años transcurridos entre ambos estudios no explicaban aceptablemente estos cambios. Posteriormente, se cae en cuenta que una no reconocida perspectiva de los investigadores era la causante del problema. La selectividad que originaba aquella perspectiva había actuado como un filtro de la realidad, filtro que para Lewis transparentaba las situaciones de conflicto intracomunitario y para Redfield las relaciones cooperativas. Indudablemente este hecho pudo ser detectado por la incompatibilidad de ambos filtros, pero ¿qué hubiera sucedido si ambos fueran idénticos? Como el problema debe ser más general que el acontecimiento expuesto, surge de lleno el problema para aquellos que no están dispuestos o en condiciones de hacer reestudios y quisieran aprovechar data recolectada ¿a qué conclusión llegaría el comparativista con respecto a Tepoztlán? En este punto nuestra discusión se centra en elaborar un procedimiento para el control de la calidad de la data, que permita minimizar la aceptación acrítica de la información contenida en otros estudios y que a la vez proporcione las bases para una codificación con fines comparativos. Los procedimientos generales están contenidos en el Handbook of Method in Cultural Anthropology (Eds. Narroll \& Cohen, 1973), específicamente en su parte séptima. Nosotros hemos convertido algunos de esos procedimientos acomodándolos para la aplicación en cuatro estudios sobre religiosidad popular. Se entiende que el procedimiento no es exclusivo para esta temática

En sus líneas centrales el procedimiento de control de calidad de la data se sustenta en un análisis del contenido en 7 categorías, que a continuación exponemos.

\section{Categorías para el aNÁlisis del CONTENIDO}

\section{IDENTIFICACIÓN:}

Incluye ficha bibliográfica completa; profesión y actividad del autor; duración temporal del estudio; tipo de auspicio y financiamiento; colaboradores, etc.

\section{Propósitos de la investigación:}

La mayor parte de las veces los propósitos se presentan implícitamente o en forma encubierta a manera de opiniones de los autores que se dejan caer fundamentalmente en las partes iniciales del estudio. 


\section{IDEAS PERSONALES DEL AUTOR:}

Por lo general esta categoría se constituye en el factor crítico para determinar los sesgos de los estudios. Aquí se incluyen las opiniones y afirmaciones que con plena gratuidad empírica emiten los investigadores.

\section{NIVEL TEÓRICO:}

¿Qué teorías sirven de marco a la investigación?; ¿qué generalizaciones recoge el autor? ¿Se presentan hipótesis? (muchas veces se presentan en forma encubierta); ¿con qué teoría se alinea el investigador?; ¿cómo son definidos los conceptos centrales?

\section{Métodos:}

Determinación del nivel de la investigación. Métodos y técnicas empleadas. Universo y muestra estudiada. Interesan especialmente los procedimientos que se emplearon para seleccionar los métodos, técnicas y la muestra.

\section{RESUltados GeNerales:}

Interesan tanto los resultados formales, reconocidos por el autor, $y$ también la extensión que se le dan a los resultados y su validez para otros grupos. Los autores muchas veces hacen observaciones críticas con respecto a sus propios hallazgos.

\section{Conclusiones:}

Se deben incluir las afirmaciones que se hacen de la realidad estudiada, nuevas hipótesis, nuevas líneas de investigación, etc.

Los siete aspectos reseñados se complementan con otros dos: en primer lugar un resumen convencional y una apreciación general del trabajo. Para ambas categorías se recomienda haber completado el análisis de contenido. El resumen debe remitirse a lo verdaderamente expuesto o reconocido por el autor del estudio, por el contrario la apreciación es reconocidamente una opinión crítica del estudio y que eventualmente sirve de referencia para otros analistas.

A continuación exponemos in extenso la aplicación de la metodología propuesta que para este caso se aplicó en importantes estudios de religiosidad popular. Como analista se desempeñó la antropóloga Vivian Saidel.

\section{Aplicaciones}

C. Lalive. El Refugio de las Masas: estudio sociológico del protestantismo chileno.

Resumen: El autor tuvo como objetivo general realizar un estudio sobre el 
movimiento pentecostal en Chile para indagar acerca de su éxito dentro de la sociedad chilena y especialmente dentro de las capas populares de la población, en contraste con otros movimientos protestantes de tipo tradicional. El autor plantea que el pentecostalismo debe fundamentalmente su éxito a dos factores: por una parte la situación anómica de la sociedad chilena que se produce luego del desmoronamiento de las estructuras tradicionales, como la gran hacienda y el patronaje; por otra parte, porque, además de este aspecto externo e histórico, el pentecostalismo, a través de la autoridad del pastor, sustituye el paternalismo autoritario del hacendado, permite una posibilidad de ascenso vertical, no existente en la sociedad global, permitiendo la integración del marginado a una comunidad, etc. En otras palabras, el éxito de este movimiento religioso es que se adapta a la situación sociocultural. En cambio, los demás movimientos protestantes representan una cultura extranjera, no chilenizada. El autor trabaja con hipótesis, comprobadas, en su gran mayoría, y utiliza tanto fuentes históricas, como de observación participante y aplicación de un cuestionario a tres muestras, con una finalidad comparativa al interior del mismo protestantismo.

\section{IDENTIFICACIÓN}

El autor es un teólogo y sociólogo suizo, profesor asistente de la Cátedra de Sociología de la Universidad de Ginebra. Su investigación fue realizada entre 1965 y 1966 con I 3 meses de terreno y el auspicio del Concilio Evangélico de Chile, y constituye parte de un programa de estudios emprendido por el Consejo Mundial de Iglesias, que abarca estudios similares en varios continentes. El autor trabajó con dos colaboradores, tanto en los aspectos teóricos como empíricos de su investigación, uno pentecostal y otro metodista. Ella fue realizada íntegramente entre adeptos de las iglesias evangélicas, específicamente entre pentecostales.

\section{Propósitos de l.a Investigiación}

2.1 Efectuar un acercamiento no teológico sobre un movimiento religioso, que sirva a la comprensión del protestantismo chileno.

2.2 Centrarse especialmente en el movimiento pentecostal (concebido como un protestantismo popular). Analizar el por qué de su éxito. Responder a si se ha inspirado en la cultura popular chilena o si es un cuerpo extraño a su medio (extranjero).

2.3 Conocer los factores que primero impidieron y luego favorecieron la implantación del protestantismo en Chile $y$, en particular, la expansión del pentecostalismo.

2.4 Conocer las fuentes de inspiración del pentecostalismo en sus formas de expresión social para determinar si ha recibido o no influencias de los modelos socioculturales dominantes en la sociedad chilena. 
2.5 Comparar los movimientos protestantes tradicionales y el movimiento pentecostal en relación a diversas materias.

\section{IdEAS PERSONALES DEL AUTOR}

“... Salgo convencido de que los fenómenos llamados carismáticos sólo en raras ocasiones son simulados. Estoy convencido que de haber sido un campesino o un obrero chileno, me habría visto cogido por la fuerza de este contagio colectivo..." (p. 20).

“... Estamos persuadidos de que el pentecostalismo no puede ser descrito sociológicamente y explicado en sí mismo, si no está al mismo tiempo situado diacrónicamente en la sociedad en cuyo seno se desarrolla. Sólo el análisis de los factores externos puede hacer comprensible la atracción ejercida por los caracteres internos del pentecostalismo sobre las masas populares" (p. 48). "La Iglesia Metodista Pentecostal, sería la primera denominación protestante verdaderamente nacional, por sus finanzas y sus dirigentes. Ahí reside la principal razón interna de su éxito futuro" (p. 45).

"Subrayamos que la sociedad chilena tradicional se caracteriza, en el nivel de los estados mentales colectivos, por su religiosidad, y hasta por una mentalidad mágica, primitiva en el sentido de Levy-Bhruhl" (p. 68).

\section{Nivel teórico}

\subsection{Teorías que sirven de marco a la investigación}

El autor, en sus antecedentes teóricos, desarrolla la situación general de Chile en la época en que aparecen los movimientos protestantes, relata sobre la base de fuentes documentales, el cisma ocurrido dentro de la iglesia metodista chilena que dio lugar al pentecostalismo chileno. La penetración protestante en Chile tuvo lugar en el siglo XIX, luego de la independencia nacional.

Sobre el nacimiento del pentecostalismo no hay demasiada información, pero se sabe que en 1909 surge de hecho la Iglesia Pentecostal, producto de una ruptura al interior de la Iglesia Metodista, debido a que esta última considera que el pentecostalismo disemina doctrinas falsas y antimetodistas a la vez que los pentecostalistas desean una renovación espiritual y mística, la cual se posibilitó a través de un jefe carismático (Hoover, metodista previamente). Aparece, según Lalive, en los momentos cuando el país sufre una etapa de transición y de anomia, producida por la dislocación de las organizaciones sociales tradicionales, en que se desmorona el sistema social familista y paternalista de la gran hacienda.

En lo interno, el pentecostalismo utiliza como principal instrumento de divulgación la predicación al aire libre ("Hablan el lenguaje popular y se dirigen a sus hermanos de clase...") (p. 67). Predicar el Evangelio no es monopolio de especialistas, ya que todo fiel puede ser predicador. Casi carente de teología, el pentecostalismo cree en la inspiración divina de la Biblia, fe en el Espíritu Santo 
el cual vive y actúa de manera espiritual (sobrenatural), en el bautismo del Espíritu Santo expresado a través de experiencias místicas extáticas, glosolalia, profecías, danzas, curación a través de la imposición de manos. En cuanto a su organización, el pentecostalismo, instaura un poder paternalista, autoritario y carismático el cual es aceptado voluntariamente por los fieles ya que se lo considera de "elección divina". Sin embargo, este poder decide a través del consenso.

\subsection{Hipótesis}

4.2.1 "El pentecostalismo se presenta como una respuesta religiosa comunitaria al abandono de grandes capas de la población: abandono provocado por el carácter anómico de una sociedad en transición" (p. 47).

4.2.2 "El éxito de esta secta, que sucede a los fracasos repetidos de las denominaciones misioneras más antiguas, descansa sobre la relación continuidad-discontinuidad que une el pentecostalismo a la sociedad y cultura ambientes" (p. 70). La continuidad, según explica el autor, se refiere a que este movimiento reconstituye la antigua sociedad señorial, dando protección y confianza en las relaciones humanas verticales y la discontinuidad se refiere a que permite una igualdad de posibilidades para los fieles, lo que no existe en la sociedad global externa.

4.2.3 "Cuanto mayores posibilidades reales y concretas de participación directa of rezca la sociedad chilena a las capas populares, más crecerá la tensión entre el pertenecer al pentecostalismo y la conciencia de ser ciudadano de un país" (p. 170). Esta hipótesis se refuerza en las conclusiones.

\subsection{Refuerzo de alguna teoría en particular}

En el texto, se reitera la idea acerca de que el pentecostalismo y su éxito en la sociedad chilena se deben a que "insuflándole finalidades y valores nuevos, el pentecostalismo ha procurado una legitimación nueva y vigorosa de la imagen persistente del patrón en la sociedad sudamericana. El pastor, personaje nuevo en la sociedad chilena, llena una función que la mutación social no ha eliminado, sino que había dejado vacante, con gran sufrimiento para los ambientes populares" (p. 116). A la vez, "si el pastor tiene el papel del patrón, este papel ha sido hecho potencialmente a todos... Perpetúa el modelo tradicional del poder, abriendo al mismo tiempo, el acceso a las funciones dirigentes" (p. 117), por parte de los postergados.

\subsection{Qué entiende el autor por religiosidad y/o religiosidad popular}

En ninguna parte de su obra el autor propone una definición. Sin embargo, podra inferirse que para él la religiosidad popular es aquella que se da en los estratos bajos de la sociedad. Lalive concibe el pentecostalismo como un protes- 
tantismo popular, pero a lo largo de su obra no desarrolla el concepto de religiosidad ni de religiosidad popular.

\section{METonos}

5.1 Nivel de la investigación: Descriptivo y comparativo.

5.2 Método usado.

5.2.1 Análisis de documentos y escritos (periódicos pentecostales, obras sobre protestantismo en Chile, informaciones estadísticas, etc.).

5.2.2 Observación participante por sus dos colaboradores (de actividades comunitarias, familias pentecostales de pastores y fieles, etc.).

5.2.3 Encuesta y entrevista (biografías pastorales, biografías y relatos de conversiones hechos por fieles, conversación con dirigentes evangélicos y no evangélicos. En resumen "con personas de toda categoría que, por su profesión, tenían cierto conocimiento del pentecostalismo y de los pentecostales" (p. 20).

Las entrevistas fueron realizadas sobre un esquema de conversación. Además se aplicó un cuestionario que versaba sobre cosmovisión, concepción de la función pastoral y percepción de otras denominaciones cristianas. La aplicación de este cuestionario se hizo a 61 pastores pentecostales chilenos y a 25 pastores presbiterianos y anglicanos, ambos grupos pertenecientes a tres provincias, Santiago, Cautín y Concepción. Además, se aplicó a 36 estudiantes de la Facultad evangélica de Teología de Buenos Aires.

\subsection{Criterio para la selección de las muestras $e$ informantes}

Se renunció a los procedimientos probabilísticos de muestreo. La elección de las provincias se hizo en función de la densidad de los protestantes y en su función de su medio socioeconómico (Santiago: urbana; Cautín: agrícola y Concepción: mixta) con el fin de determinar si este factor influía en las opiniones pastorales. La muestra de estudiantes de Teología se eligió para constituir un grupo de referencia con respecto a las posiciones pentecostales y para detectar cambios de opinión respecto al protestantismo tradicional por parte de las generaciones más jóvenes. La elección de estas 3 muestras responde a un interés comparativo en relación a las respuestas dadas al cuestionario aplicado.

\subsection{Técnicas:}

Grabación de las entrevistas.

El cuestionario, por su parte, consta de 55 preguntas con algunas modificaciones hechas para cada una de las muestras a las cuales se aplicó. Contiene respuestas cerradas (sí/no) y de alternativas (estereotipadas), conteniendo un espacio en blanco para permitir la aclaración de la respuesta. 


\section{Resultados Generales}

6.l Sobre la base a los censos oficiales: El grupo de los pentecostales y de las denominaciones de santificación, compondrían actualmente el $87 \%$ del cuerpo protestante o evangélico chileno... "Comprobamos aquí una tendencia sociológica del protestantismo chileno: el crecimiento numérico es tanto más notable cuanto más joven es la denominación" (p. 53).

6.2 El protestantismo no es específicamente rural ni específicamente urbano. Las condiciones socioeconómicas de las provincias de la muestra no influirían sobre las opiniones pastorales.

6.3 Entre los pastores pentecostales hay un fuerte rechazo (mayor que en las demás muestras) respecto a la participación sociopolítica del fiel. Se condena el fenómeno político como tal por considerárselo mundano.

6.4 En Concepción, donde la afiliación sindical es mucho más fuerte que en las otras dos provincias, las iglesias son más permeables a los problemas de la comunidad ambiente porque de hecho sus fieles participan de dichos problemas.

6.5 En relación a aspectos ecuménicos y teológicos aludidos en el cuestionario:

Las tres muestras testimonian espíritu ecuménico, en cuanto ninguna reduce el Corpus Christi al tipo denominacional que representa.

Están de acuerdo en excluir a los Testigos de Jehová, a los mormones y son casi igualmente exclusivos respecto a los adventistas.

El pentecostalismo no se considera exclusivo de la salvación, pero pretende ser el más perfecto de los componentes del Cuerpo de Cristo. El papel discriminante lo representa la Iglesia Católica, con excepción para los estudiantes de teología. Esto sería la señal de una ruptura de parte de las nuevas generaciones protestantes tradicionales con la actitud tradicional del protestantismo en América Latina.

\section{Conclusiones}

Sobre el éxito del pentecostalismo en comparación con el resto de los movimientos protestantes tradicionales (en Chile):

El pentecostalismo se ha enraizado en la cultura nacional y esto explicaría su éxito. Son los únicos que disponen de una organización adaptada al contexto cultural y social. Constituye un modelo ejemplar de protestantismo sudamericano.

Surge en el momento en que se desmorona el sistema familista y paternal que prosperaba en la gran hacienda. Como modelo de sustitución de estas estructuras sociales desmoronadas en las clases populares marginales, el pentecostalismo of rece un mecanismo de solución dentro de una situación anómica de transición.

El estancamiento de los movimientos protestantes tradicionales se explica 
por el hecho de que éstos sirven de agencias a organismos norteamericanos, reforzando así la imagen que la sociedad sudamericana tiene de ellos, considerándolos como una religión extranjera.

- El pentecostalismo mantiene con la sociedad chilena relaciones dialécticas de continuidad-discontinuidad, de préstamo y rechazo de los esquemas socioculturales ambientes. Es una ideología del orden y de la conservación y no del movimiento ni del cambio.

Planteamiento de hipótesis en las conclusiones

Si no intervienen cambios notables en la estructura de la sociedad chilena, el pentecostalismo tenderá a evolucionar lenta e irregularmente hacia el tipo denominacional, ya que "es inevitable que los cambios en la sociedad global repercutan sobre el pentecostalismo e influyan sobre su evolución” (p. 267).

\section{A. Cruz, La Religiosidad Popular Chilena}

Resumen: Los propósitos fundamentales del trabajo de Antonio Cruz son:

1. Definir lo que se entiende por religiosidad popular chilena, partiendo con una definición provisoria para ver si se verifica a la luz de su investigación o si es necesario una definición nueva. El autor finalmente verifica su definición provisoria.

2. A nivel de hipótesis, Cruz plantea posibles correlaciones entre la religiosidad popular - más mágica que religiosa-y la necesidad psíquica de seguridad. Comprueba esta correlación estadísticamente y explica que la inseguridad constituye una característica de la personalidad básica chilena, debido a condiciones estructurales que producen tensión e inseguridad en el hombre que reside tanto en contextos rurales, como en contextos marginales y urbanos. La apariencia católica de la religiosidad popular chilena se debe a una baja internalización del catolicismo doctrinal debida a que los evangelizadores españoles dieron más importancia al aspecto ritual y exterior del catolicismo, de manera que en lo interno lo doctrinal se mezcló con las pautas religiosas mágicas aborígenes preexistentes.

3. A nivel de hipótesis, igualmente, Cruz plantea posibles correlaciones entre el contexto urbano, marginal o rural y el grado de religiosidad tradicional o secular predominante. Suponiendo que esta última se daría mayormente en el contexto urbano, a diferencia del contexto rural en el cual se daría más el tipo de religiosidad tradicional. Esta hipótesis no se comprobó en la investigación, tal vez debido a que las comunas urbanas consideradas, no eran lo suficientemente urbanas. El instrumento de recolección de datos fue una entrevista semiestructurada aplicada, considerando los tres contextos en conjunto, a una muestra de 630 personas. 


\section{IDENTIFICACIÓN}

Su investigación forma parte de un estudio sociológico de carácter comparativoe internacional sobre el tema de la religiosidad popular, emprendido por la Federación Internacional de Institutos de Investigaciones Sociales y Sociorreligiosas (FERES), que comenzó en 1969 en cinco países de América (Brasil, Colombia, México y Venezuela), patrocinado por la Conferencia Episcopal Latinoamericana (CELAM) y financiado por la Fundación Alemana Adveniat, con el fin de elaborar y promover a nivel continental una política de acción pastoral en beneficio de las masas latinoamericanas. Por su naturaleza comparativa, los diversos estudios se realizaron en forma simultánea y coordinada de acuerdo a un mismo diseño de investigación. El autor de la investigación chilena sobre religiosidad popular es un sociólogo chileno y en la recolección de la información empleó encuestadores universitarios.

\section{Propósitó de la investigación}

2.1 Realizar un estudio exploratorio con el fin de responder acerca de lo que es o se entiende por religiosidad popular.

2.2 Hacer referencia a lo que debería ser el universo o campo de análisis de un estudio sobre religiosidad popular o de catolicismo popular.

2.3 Analizar ciertas expresiones populares religiosas que están dentro de la realidad chilena y que se incluyeron en el estudio además del catolicismo popular, de tipo secular.

2.4 Dar respuesta teórica y empírica a dos hipótesis de trabajo (ver hipótesis sobre la religiosidad popular).

2.5 Enriquecer el conocimiento y la comprensión de fenómenos religiosos populares en Chile.

\section{IdeAs PERSONALES DEL AUTOR}

"Lo que aquí llamamos religiosidad constituye una totalidad que incluye y desborda al catolicismo que es sólo una de las muchas formas de expresión de la religiosidad individual o social" (p. 5).

Al hacer referencia a las razones para incluir comportamientos seculares: “... Derivan de lo que llamamos su parentesco teleológico y motivacional con ciertas formas católicas... A causa de dicho parentesco, los recursos seculares coexisten y están sincretísticamente unidos con ciertas formas católicas (p. 8). Otro motivo se relaciona con "el actual proceso de cambio religioso o de secularización y el posible rol de sustituto religioso que les cabría desempeñar en él a los gestos seculares..." (p. 8).

"Pensamos que el desinterés de vastos sectores sociales urbanos por la religión institucional se debe principalmente al rezago cultural de muchas pautas de conducta religiosa tradicional, en cuanto interpretan o expresan 
cada yez menos los verdaderos valores, intereses o necesidades de la personalidad urbana contemporánea (p. 13).

\section{NIVEL TEÓRICO}

El autor combina dos enfoques teóricos como modelos para analizar la religión: El mod̄elo estructural-funcional y el modelo de la personalidad básica. Considera necesario acudir al sistema de la personalidad popular chilena, que impulsa a las masas de uno y otro contexto a comportarse de un modo popular desde el punto de vista religioso. El autor, basándose en Kardiner y otros, subraya la acción recíproca entre individuo y cultura, como efecto de las instituciones primarias, que imponen al individuo cierta conducta y como causa de las instituciones secundarias (práctica mediante las cuales la personalidad básica reacciona a lo primario, conductas no institucionalizadas, aquello que tiene carácter de consecuencia). El autor propone un enfoque psicológico del fenómeno religioso popular chileno, considerando que "en el interior de una cultura, las formas y contenidos religiosos (...) son expresión de las características psicológicas de la personalidad básica o media del grupo o sociedad a que pertenece dicha cultura" (p. 55).

Según Cruz, la personalidad básica sería una variable independiente que tendría poder explicativo respecto de la religiosidad popular. La característica de esta personalidad básica "nos parece ser el sentimiento de ansiedad y la actitud de inseguridad, colectivamente compartidas por las masas chilenas de uno u otro contexto sociocultural. Esta ansiedad e inseguridad colectivas constituyen, a nuestro parecer, el soporte motivacional y valoral de la religiosidad popular" (p. 60).

\section{I Hipótesis: (Explícitas)}

4.1.1 "A mayor religiosidad popular, mayor motivación de seguridad psíquica. A menor religiosidad popular, menor motivación de seguridad psíquica.

4.1.2 "La tasa de religiosidad tradicional es mayor en el contexto rural que en el suburbano y la de éste, a su vez, es mayor que la tasa de religiosidad tradicional del contexto urbano que en el suburbano y la de éste, a su vez, es mayor que la tasa de religiosidad secular de contexto rural".

4.1.3 Otra hipótesis se refiere al reemplazo de las formas religiosas tradicionales por otras modernas y de apariencia secular.

Las dos primeras hipótesis formuladas, se tratan de comprobar de manera tanto teórica como empírica (ver metodologia).

\subsection{Refuerzo de alguna teoría en particular}

El autor refuerza fundamentalmente, a través de su marco teórico, la idea de personalidad básica, la interacción recíproca entre individuo y cultura, el planteamiento de instituciones primarias y secundarias y la teoria estructural-funcionalista. 
Resalta además, la necesidad de realizar estudios psicosociológicos, dado que la sociedad, en última instancia, se conforma mediante individuos. Sus motivaciones y necesidades serían las que crearían y mantendrían a la cultura.

\subsection{Qué entiende el autor por religiosidad y/o religiosidad popular}

"Para nosotros, la verdadera esencia de la religión es lo sagrado y no lo sobrenatural (...). Lo sagrado comprende un referente más amplio. Por religión entendemos un sistema de creencias, valores o ritos que apuntan hacia entıdades u objetos tanto del mundo natural como sobrenatural, siempre y cuando sean tenidos como sagrados por un individuo o una comunidad de adoradores... El signo de lo sagrado no lo dan las cosas en sí mismas sino la naturaleza de las actitudes y los sentimientos que las refuerzan. El carácter de lo sagrado consiste, pues, en actitudes mentales sostenidas emocionalmente..." (p. 10).

El autor desea llegar a una definición de tipo empírico acerca de lo que sería la religiosidad popular chilena, sea reforzando definiciones previas o bien formulando una nueva definición a la luz de los datos recolectados por su investigación empírica. Con esta finalidad, Cruz comienza definiendo a priori la religiosidad popular chilena, desde un punto de vista sociológico.

"Es el conjunto de creencias, valores, símbolos, sentimientos, motivaciones y ritos de origen tanto católico como mágico y secular, generalmente institucionalizados, mediante los cuales las mayorías urbanas, suburbanas y rurales de nuestro pais, de un modo uniforme -con ligeras variaciones locales- expresan su relación con una esfera sagrada compuesta por entidades y objetos tanto del mundo sobrenatural como del natural. Estos contenidos y formas religiosas de expresión popular, forman un subsistema religioso cuyas principales características son: en lo externo, sincretismo de formas mágicas con formas seculares y otras propias del catolicismo "primitivo" o del actual vigente a nivel oficial; con predominio de estas últimas sobre las primeras, lo que le confiere a dicho subsistema una apariencia exteriormente católica. En lo interno, la religión popular se caracteriza por una concepción monista de Dios y las demás entidades sobrenaturales - como "naturalmente" presentes en el cosmos- y por una utilización mágica de los mismos para obtener fines empíricos. En consecuencia, la religión popular, no obstante su apariencia católica externa, en lo interno conserva poco de la doctrina y de la escala de valores y motivaciones del catolicismo oficial" (pp. 115-116).

\section{METODOS}

5.1 Nivel de la investigación: Exploratorio. El autor utiliza hipótesis por considerar que respecto a algunos puntos hay antecedentes teóricos suficientes como para hacerlo y además por considerar que el planteamiento de hipótesis es muy importante para todo trabajo científico. 


\subsection{Métodos usados:}

-Entrevista semiestructurada aplicada a 630 personas pertenecientes a contexto urbano, suburbano y rural.

5.3 Criterios para la selección de informantes:

El universo se redujo en base a los siguientes criterios: contexto rural y urbano. Una vez elegidos los subuniversos católico y no católico, se dividió internamente a ambos en 2 áreas: urbana y rural, utilizando índices demográficos y económicos. Si bien el área marginal o suburbana fue eliminada del proyecto de feres (por razones económicas y por poca homogeneidad social y cultural), Antonio Cruz amplió el universo del proyecto en Chile, dada la gran concentración de masas chilenas en dichos contextos y además porque permitía crear una escala de urbanización para analizar dinámicamente la religiosidad popular y concluir respecto al proceso de secularización.

Otra medida de reducción fue el criterio de la edad. Al interior de cada uno de los cuatro subuniversos se consideró sólo a la población adulta de 18 o más años. De los cuatro subuniversos se extrajo una muestra de cada uno de ellos.

\subsection{Técnica:}

Se utilizó una entrevista semiestructurada, compuesta de preguntas cerradas y preguntas abiertas a mitad de cada tipo.

El autor comenta que el factor seguridad-inseguridad (psicológico) no pudo medirse más allá de los motivos declarados por los entrevistados en declaración verbal y consciente, por lo tanto la validez de la medición empirica de esta variable es relativa.

\section{Resultados generales}

El autor se ocupa de los datos más significativos recolectados a través de la entrevista, relacionados con los 3 problemas de investigación:

La información sustantiva que permita respuesta o solución empírica a lo que se entiende por religiosidad popular chilena.

A este respecto, Cruz comprueba que su definición provisoria sobre la religiosidad popular chilena es válida.

El autor llega a esta afirmación, al constatar que los entrevistados, en su gran mayoría: se debaten al margen del catolicismo doctrinal, consideran que Dios se manifiesta a través de fenómenos naturales, recurre a las entidades sobrenaturales para solucionar diversos problemas (lo que es propio de los sistemas mágicos). Respecto a los ritos más practicados, los ritos de origen católico casi no tienen ninguna vigencia a diferencia de los ritos de tipo católico popular. Los santos son altamente venerados al igual que la Virgen (como mediadores ante la Fuerza Sagrada Superior). Las mandas y peregrinaciones no tendrían hoy la misma vigencia que antaño e igualmente el uso de sacramentales u objetos sacrales. Lo 
que sí tiene influencia es el culto a los difuntos (ingrediente esencial del sistema mágico de las sociedades primitivas). Las prácticas seculares más importantes no parecen tener gravitación, a excepción de la lectura de horóscopos.

\section{Conclusiones}

Verificación empírica de la hipótesis: "A mayor religiosidad popular, mayor motivación de seguridad psicológica. A menor religiosidad popular, menor motivación de seguridad psicológica".

La motivación de seguridad está definida por el autor como la búsqueda de alguna meta capaz de brindar alivio al yo, instrumentalización de la divinidad para satisfacer necesidades adaptativas más que expresivas.

Verificación empírica de la hipótesis: "La tasa de religiosidad tradicional es mayor en el contexto rural que en el suburbano y la de éste, a su vez, es mayor que la tasa de religiosidad de contexto urbano". "La tasa de religiosidad secular es mayor que la tasa de religiosidad secular de contextor rural".

No hay asociación estadísticamente significativa entre la religiosidad tradicional y el contexto rural-urbano ni tampoco entre lo urbano y la religiosidad secular. Al avanzar el continuo rural-urbano no decrece la tasa de religiosidad tradicional ni aumenta la de religiosidad secular. Esta hipótesis, por lo tanto, se rechaza. El autor plantea que quizás debió incluirse a las grandes ciudades chilenas dentro del universo, como Santiago, Valparaíso, Concepción, que es donde realmente se da el estilo de vida secular.

A. Bentué. Religión y Marginalidad Social en la Población La Victoria, de Santiago (Chile) y reflexión teológica

RESUMEN: El autor tuvo por objetivo principal relacionar la situación de marginalidad social con la religiosidad. Para ello analiza el tipo de religiosidad existente en la población La Victoria, año 1969. Utiliza como método los resulta-' dos de una encuesta sociológica sobre religiosidad en dicha población (datos secundarios que el autor reordenó), hace uso de entrevistas personales con líderes de allí y complementa todo esto con la observación directa. Posteriormente, compara los resultados de La Victoria con los obtenidos por Cruz respecto a la religiosidad media del país con el fin de ver si en la población estudiada la religiosidad presenta características especiales. Ante lo afirmativo de este planteamiento, el autor supone que la religiosidad de La Victoria está relacionada con la situación marginal de los pobladores y con su falta de conciencia de clase. La religiosidad en La Victoria sería utilizada como una vía de solución a problemas socioeconómicos propios de la situación marginal, complementada con prácticas individualistas, fundamentalmente a través de mandas con el fin de obtener beneficios. El poco grado de compromiso social y de participación 
política de los pobladores, sirve al autor como base para comprobar que junto a una religiosidad causal, y no de sentido, se presenta falta de conciencia de clase.

Desde un punto de vista teórico, el autor se dirige hacia la fenomenología tanto filosófica como religiosa, las cuales van más al sentido que hacia las causas y explicaciones de los fenómenos.

El autor propone una religión a nivel del sentido y no a nivel de la solución de problemas intramundanos, como la marginalidad, la cual debe solucionarse a través de la conciencia de clase transformadora de las condiciones de vida del hombre marginal.

\section{IDENTIFICACIÓN}

El autor es un teólogo español, que en 1969 decidió vivir en La Victoria, de donde surgió su interés por esta temática de tesis. No hace referencia en la obra respecto a la duración de la investigación ni a su financiamiento, parece no haber trabajado en equipo, sino solo. Los datos que entrega su investigación corresponden a la situación de la Población La Victoria en los años 1969, hasta comienzos de 1970 .

\section{Propósitos de la Investigación}

Podría decirles que el objetivo general del autor fue: Relacionar la situación marginal de La Victoria con la religiosidad de sus pobladores, precisando los elementos característicos de la religiosidad existente en un contexto marginal.

Para lograr tal propósito, el autor, desde un punto de vista teórico, desarrolla el fenómeno de la marginalidad y luego el de la religiosidad. Posteriormente, aplica ambos fenómenos a la situación de La Victoria.

\section{IDEAS PERSONALES DEL AUTOR}

Sobre marginalidad: a) "El subdesarrollo no es una etapa que simplemente precede al despegue hacia el desarrollo capitalista, sino que es una situación de dependencia provocada históricamente por la dominación económica ( $y$ a menudo también política) de los países industrializados con respecto a los demás países del mundo" (p. 17). "Es al interior de este producto del desarrollo capitalista que encontramos todavía un subproducto: la marginalidad social" (p. 21). b) "La falta de conciencia de clase hace muy difícil la integración de los marginados a las luchas sociales con vistas a la transformación real de las relaciones socioeconómicas..." (p. 25). "El marginal social tiene, naturalmente, conciencia de su situación en absoluto privilegiada y es también consciente del hecho que una tal situación es semejante a la de muchos pobladores de otros lugares" (p. 27). Pero, señala el autor, el que el marginado pelee por ciertas reivindicaciones no significa que tenga conciencia de clase, ya que la conciencia de clase auténtica es una conciencia histórica y política que busca establecer una comunidad social más allá 
del mismo sistema capitalista (cita a Lucaks). "La conciencia histórica de las masa marginales no es fundamentalmente culpa suya, sino que es sobre todo el efecto más funesto del sistema que es la causa de la marginalidad" (p. 32).

Sobre la población La Victoria: "Un tal optimismo (el autor comenta que la mayoría de los encuestados declara ser feliz) oculta cierta limitación de las necesidades de los pobladores. Éstos se han acostumbrado a vivir con el mínimo indispensable, no tienen grandes aspiraciones y, por lo tanto, no tienen tampoco grandes frustraciones. No tienen realmente conciencia de su propia miseria económica y social" (p. 69). "En el optimismo de muchos pobladores puede encontrarse cierto mecanismo psicológico de autodefensa" (p. 74).

Sobre la religiosidad: "Estoy convencido de que, en las formas religiosas propias de la situación marginal hay mucho más que ignorancias precientífica" (p. 80). "Lo determinante en el subdesarrollo marginal es la ausencia de conciencia de clase del subproletariado que retarda la transformación hacia un nuevo tipo de sociedad sin marginalidad. Aquí también la religión individualista (formalista o mágica) puede contribuir a mantener la marginalidad bloqueando la posibilidad de una conciencia de clase del marginado" (p. 186).

\section{NiVEL TEÓRICO}

\subsection{Teorías que sirven de marco a la investigación:}

El autor manifiesta interés por realizar un desarrollo teórico tanto de la marginalidad como de la religiosidad.

Marginalidad: Hace referencia general sobre ésta como producto de una situación de dependencia que resulta del sistema capitalista. Hace referencia a las contradicciones del capitalismo, desarrolla la marginalidad en relación a clase social, conciencia de clase, etc. En este aspecto, cita críticamente a Rostow y favorablemente a Lucaks (entre otros).

Religiosidad: Recurre a 3 fuentes fundamentales:

4.1.1 Análisis estructuralista del mito, según L. Strauss, cuya idea fundamental es que en la elaboración mítica, aparentemente libre y descabellada, habría leyes operando a un nivel profundo, inconsciente, las cuales son un reflejo del espíritu humano. El hombre estaría determinado por leyes idénticas de funcionamiento lógico a nivel del inconsciente. El código inconsciente predetermina todo el pensamiento humano y todo su lenguaje. El autor considera que el estructuralismo, siendo muy legítimo y fecundo, no da cuenta del sentido del mito ni del sentido de los fenómenos religiosos.

4.1.2 Fenomenología religiosa, según Mircea Eliade, que desarrolla para las religiones primitivas la diferencia entre el tiempo sagrado, original y real y el tiempo profano actual o histórico. Los mitos cuentan el origen de la realidad profana y los ritos regeneran el tiempo profano al conmemorar el tiempo mítico. A través de ello, el primitivo busca el fundamento o sentido de su vida. El autor 
concluye que "el lenguaje mítico-religioso, aun cuando en sus formas lingüísticas o ideológicas pueda responder a leyes inconscientes del pensamiento humano, en su intencionalidad más profunda puede expresar la nostalgia ontológica del fundamento de la realidad" (p. 117).

4.1.3 Fenomenología filosófica, de acuerdo con Heidegger fundamentalmente, el cual diferencia entre el hecho de la existencia, lo óntico y el sentido de la existencia, lo ontológico. El existencialismo descubre que el fundamento del hombre es la inhospitalidad, la ausencia de fundamento del ser en el mundo, su carácter temporal.

El autor recurre a estas fuentes teóricas con la finalidad de distinguir entre las causas del fenómeno religioso, susceptible de ser enfocadas por las ciencias positivas, como la sociología, y el sentido del fenómeno religioso: lo teológico y fenomenológico. Ambas son para el autor interpretaciones válidas.

"Existe una relación inversa entre conciencia de clase y marginalidad social. Es decir, habría una correspondencia estrecha entre marginalidad y ausencia de conciencia de clase" (p. 26).

Esta hipótesis está enunciada explícitamente por el autor. De manera más implícita el autor desea demostrar que hay una relación entre la situación marginal y el tipo de rligiosidad de La Victoria.

La primera hipótesis la comprueba a través de un análisis reflexivo sobre el concepto de conciencia de clase y la situación marginal. La segunda hipótesis a través de su investigación empírica.

\subsection{Refuerzo de alguna teoría particular}

Como ya señalara, el autor propone un análisis abierto del fenómeno religioso que considere tanto la perspectiva sociológica como no sociológica en la medida en que se requiera, objetividad sin reducir los fenómenos religiosos a postulados unilaterales.

4.3 Qué entiende el autor por religiosidad y/o religiosidad popular

“Usaremos indiferentemente los términos religión y religiosidad. Aquí no nos interesa dilucidar las diferencias que pueda haber entre esas dos palabras. Lo que constituye el objeto de nuestra reflexión es más bien el contenido fenomenológico de lo religioso. Por otra parte, el concepto de religiosidad implica necesariamente el de religión y viceversa" (p. 87). Analiza el concepto de religión desde dos puntos de vista diferentes: Religión concebida como la manifestación de lo sagrado y religión concebida como una ciudadela de esperanza construida al borde de la desesperación (o sea como "respuesta o solución a enigmas sobre el origen de ciertos fenómenos") (p. 93).

El autor considera ambiguas ambas definiciones. 


\section{MÉtodos}

5.1 Nivel de la investigación: Descriptivo y explicativo.

5.2 Método usado:

Encuesta sociológica.

Entrevistas personales con 10 líderes poblacionales.

Observación directa.

5.3 Criterio para la selección de informantes.

El autor, respecto a la encuesta, supone un sondeo aleatorio o probabilista que permitiría extrapolar la media del grupo encuestado o la media real de la población total. El autor utilizó los resultados de una encuesta aplicada con anterioridad, dentro de La Victoria, por profesores universitarios (datos secundarios), de manera que no hay mayores antecedentes a este respecto.

Además de la utilización de datos secundarios, el autor realizó entrevistas personales a 10 miembros de La Victoria, de alta representatividad a nivel de liderazgo (dirigentes de Junta Vecinal, Centro de Madres, Parroquia Católica, Misión Evangélica Pentecostal, Partidos políticos, Club de Abstemios, etc.). Se infiere que su universo de estudio fue la población La Victoria por sus características de marginalidad.

\subsection{Técnicas.}

Usa datos secundarios provenientes, como ya se mencionará, de 93 encuestas aplicadas dentro de La Victoria. El autor reordenó las preguntas de la encuesta original, resultando un total de 170 preguntas divididas en dos partes: una sobre la situación socioeconómica y sociocultural de los pobladores encuestados y la otra sobre su religiosidad.

La encuesta estaba estructurada según preguntas de respuesta afirmativa o negativa y de tipo escalar: desde todos los días a nunca, por ejemplo. El autor señala que le fue difícil categorizar las respuestas de este modo ya que en el instrumento original predominaban las preguntas abiertas.

Posteriormente, el autor compara sus resultados con los datos sobre religiosidad popular chilena en general, recurriendo al trabajo de Antonio Cruz.

\section{Resultados generales}

En La Victoria había un $75 \%$ de católicos y un $16,1 \%$ de evangélicos pentecostales.

6. I La práctica religiosa católica es más bien personal (mandas, gran devoción a las ánimas, de posible influencia indígena dada la predominancia de origen campesino de los pobladores) y más mágica que religiosa, con poco compromiso social. Por su parte, los pentecostales ayudan a los miembros de su iglesia y a otros, sin participar en actividades sindicales ni políticas. La participa- 
ción en las actividades de la iglesia es ambigua desde el punto de vista del compromiso social. Dice el autor que "no puede hablarse aquí de relación entre religiosidad y compromiso social".

6.2 La religiosidad de la mayor parte de las personas de La Victoria consiste en un tipo de devoción tendiente a la autoconsolación y a la obtención de ayuda sobrenatural en las necesidades concretas individuales y familiares.

6.3 La religiosidad de la población es más extraeclesial que la religiosidad media del país (más devociones sobre todo). Los no creyentes son notablemente inferiores en La Victoria que en la media del país.

"Puede concluirse, por lo tanto, en forma general, que los elementos característicos de la religiosidad en el contexto marginal son los mismos que los de la religiosidad media del país, pero mucho más acentuados" (p. 180). Estas afirmaciones el autor las extrae de su comparación con los datos dados por Cruz.

6.4 La religiosidad de los pobladores toma sobre todo el carácter de utilización personal de una fuerza superior que viene a socorrernos para ayudarnos con los beneficios que la sociedad no nos da. Sirve para ayudar al bienestar en este mundo.

\section{Conclusiones Generales}

7.1 La marginalidad se caracteriza por una situación de miseria económica y de dependencia de los países subdesarrollados que constituye un subproducto del sistema capitalista. Esta marginalidad se mantiene debido a la falta de conciencia de clase de los marginales, que crea intereses individualistas de sobrevivencia y no conciencia comunitaria de clase.

7.2 La religiosidad en el medio marginal se caracteriza por ser individualista. El individuo busca el auxilio de fuerzas sobrenaturales. Hay una amplia creencia de tipo animista y el sentimiento fatalista de un destino inmutable en la propia vida.

7.3 Por lo tanto, la religiosidad de los pobladores tiene un rol psicosocial de adaptación a su contexto marginal. Es un medio de adaptación utilizado por la ausencia de conciencia de clase, pero que a la vez puede bloquear dicha conciencia.

\section{Parker, C. et al. Rasgos de Cultura Popular en Poblaciones de Pudahuel}

RESUMEN: La investigación llevada a cabo por un equipo de profesionales y agentes pastorales, tenía como objetivo general conocer la realidad cultural de un conjunto de poblaciones ubicadas en la zona oeste de Santiago (Pudahuel) y constituyó una iniciativa del Arzobispado de esta zona. Los propósitos eran, en base al conocimiento obtenido a través de la investigación sobre la realidad poblacional, aportar a la formación de los agentes pastorales que allí trabajaban y a la vez re-evangelizar a partir de la misma realidad estudiada. Mediante una 
encuesta, se indagó sobre algunos aspectos de las creencias religiosas, rasgos mágicos en el pensamiento popular, aspectos de convivencia cotidiana en la vida poblacional, roles del hombre y de la mujer en la clase popular, problemas de supervivencia y elementos de racionalidad en la accion social, conciencia social, orientaciones políticas, etc. Las respuestas se transformaron en frecuencias y porcentajes y se cruzaron con variables de identificación (a través de computadora). La muestra debía ser "representativa", de manera que fue constituida por personas que cumplieran ciertos requisitos (ver criterios para la selección de los informantes). Esta investigación tuvo un carácter exploratorio y plantea hipótesis interpretativas de los resultados obtenidos. Respecto a la religiosidad, que es sólo uno de los diversos temas tratados por la investigación, puede decirse que presenta vestigios de rasgos mágicos, es poco cristiana, y más bien centrada en Dios y María. Algunas variables, como el sexo y otras, parecen influir en el tipo de creencias. El autor, en base a los resultados, construyo 3 tipologías de creyentes: por tradición, por necesidad y por experiencia. El autor relaciona la religiosidad poblacional con la situación de marginalidad que las caracteriza.

\section{IDENTIFICACión}

Esta investigación se llevó a cabo por un equipo de investigación a cargo de un sociólogo (PARKer), un sacerdote, un psicólogo y un economista. En el diseño e interpretación de la encuesta participaron, además, aportaron un psicólogo y 2 teólogos y unos 18 agentes pastorales en total. Las instituciones que aportaron al trabajo fueron: Novib (Holanda), Broederlijk (Bélgica), Comite Catholique contre la Faim et pour le Development (Francia) y Solidaridad (Holanda). El equipo trabajo durante 2 años, de manera no demasiado continua: “... debemos atribuírsela a las deficiencias que hubo en un comienzo para armar el equipo de investigación debido a la falta de continuidad y a la rotación de varios de ellos" (p. 7).

El origen de este proyecto se encuentra en los años 1976-1977, en un sínodo realizado por la Zona Oeste del Arzobispado, en el cual se concluyó que era necesario que las acciones sacerdotales y religiosas respondieran a los rasgos culturales característicos de los habitantes de la zona, así como a su mentalidad e inquietudes. Para ello era necesario estudiar la realidad del sector.

\section{Propósitos de la Investigación}

Conocer la realidad cultural de la zona oeste, del modo más amplio posible. Todo aquello que es inherente a su forma de vida.

Detrás de este objetivo se encuentra un objetivo más profundo que se refiere a:

2.1 Interés de formar y evangelizar a partir de este mayor conocimiento, para evangelizar en profundidad la cultura del hombre, $y$ 
- Aportar a la formación de los agentes pastorales que participaron en la investigación, explorando las posibilidades que ofrece una investigación como metodología de formación.

\section{IdeAs PERSONALes del Autor (Autores)}

“... Al vivir en una población marginal se adquiere una visión de los problemas de las clases populares que debe ser tomada en cuenta para decidir sobre qué investigar y los métodos para hacerlo..." (p. 8).

“... Debemos hablar con cierta reserva de una cultura popular urbana... De los progresos materiales, beneficios sociales o culturales que caracterizan a la ciudad moderna, estas poblaciones tienen poco o nada. Se trata más bien de un "subproducto" de los procesos de industrialización y urbanización en nuestras sociedades dependientes. Se trata de un pueblo que históricamente ha sido obligado a emigrar del campo y al que se mantiene al margen de la sociedad capitalista moderna. Su marginalidad no es sólo física sino también sociocultural" (p. 7).

"La dimensión religiosa es importante dentro de la cultura popular que estamos investigando... Sin embargo, tampoco puede afirmarse que la cultura que estamos investigando sea una cultura "religiosa", en el sentido que lo religioso sea el eje articulador de los distintos campos culturales" (p. 23).

\section{Nivel teórico}

No hay un marco teórico sistemático, sino más bien implícito, dada la amplitud de la temática abordada. La religiosidad es sólo uno de los múltiples aspectos abordados en esta investigación sobre la realidad poblacional, desde un punto de vista cultural.

\section{1 Hipótesis:}

Si bien esta investigación, al ser exploratoria, no pretende comprobar hipótesis, se plantean sobre todo algunas con fines más bien interpretativos o bien de manera implícita.

La actual cultura popular está sometida a presiones desintegradoras y marginalizantes.

Las hipótesis interpretativas serán señaladas en los resultados generales.

4.2 Refuerzo de alguna teoría en particular:

No hay ningún refuerzo teórico especial que guíe la investigación.

4.3 Qué entiende el autor por religiosidad y/o religiosidad popular:

No se plantea de manera explícita ninguna definición conceptual al respecto, salvo en términos de la marginalidad. 


\section{MEtodos}

\subsection{Nivel de la investigación:}

Exploratoria y participativa (de investigación y formación).

\subsection{Método usado:}

Se aplicó una encuesta con preguntas sobre identificación del encuestado (12 preguntas cerradas referidas a edad, sexo, trabajo, religión, educación, etc.) y una entrevista con 187 preguntas abiertas, acerca de una diversidad de opiniones y conductas (medios de comunicación social, mundo cultural, tiempo libre, religiosidad, etc.). Ambos instrumentos se aplicaron durante sesiones (3 o 4) de una hora y media cada una. Las afirmaciones del encuestado debían transcribirse tal cual eran, con la menor interferencia posible por parte del encuestador. Los encuestadores fueron 14 agentes pastorales que trabajan en el sector, varios de ellos extranjeros. Las encuestas se realizaron en septiembre de 1978 y marzo de 1979.

Las respuestas se clasificaron según sus tendencias y semejanzas, estableciéndose categorías de respuesta. Se asignaron códigos, de este modo se pudo cuantificar y trabajar con datos numéricos. Los datos fueron procesados por computadora, obteniéndose frecuencias, porcentajes y algunos cruces. Se eligieron del total las preguntas ejes, o sea aquellas que entregaban datos de mayor riqueza y profundidad. El cruce fue hecho en base a instrucciones. Las frecuencias y cruces de variables fueron perfilando ciertas tendencias en la muestra.

5.3 Criterios para la selección de los informantes:

Con el fin de obtener los datos, se instruyó a los entrevistadores para que escogieran 10 sujetos que cumplieran con los siguientes requisitos:

5.3.1 Cinco debían ser hombres y 5 mujeres.

5.3.2 Tres de los 10 debían estar sin ocupación estable (dos hombres y una mujer).

5.3.3 Sólo una de las 10 personas debía ser activa socio-religiosamente a través de cualquier institución u organización protestantes.

5.3.4 Dos personas debían estar entre los 15 y 20 años, tres entre los 21 y los 30 años, tres entre los 31 y 40 años y dos entre los 40 y 50 años.

(140 encuestas originales).

La muestra pertenece a un conjunto de poblaciones que bordean la ribera sur del Mapocho, en el Decanato Pudahuel Norte. Se trata de un cordón poblacional de la periferia poniente del Gran Santiago, ubicado en el límite norponiente del territorio pastoral de la Vicaría Zona Oeste del Arzobispado de Santiago. Es un sector poblacional bastante homogéneo, originado de una operación sitio o de una toma de terrenos durante el gobierno de E. Frei, con una precaria situación económica general y malas condiciones de higiene ambiental. 


\section{Resultados Generales}

Los datos obtenidos a través de la encuesta se refieren a creencias (área intelectual-reflexiva) de la vida religiosa. La religión como práctica queda inexplorada en este estudio.

Un 91,4 de la muestra se declaran creyentes. Parker distingue tres tipos de creyentes: por tradición, por necesidad y por experiencia, explicando que se trata de orientaciones religiosas básicas que coexisten en la cultura popular poblacional, que probablemente jamás se dan en estado puro en un mismo individuo. El autor, en base a los datos obtenidos a través de la encuesta aplicada, construye un tipo de creyente típico de cada clase. El creyente por tradición (45\% de la muestra) y típico sería una mujer mayor de 41 años, con máximo de $2^{\circ}$ de humanidades, cesante o con trabajo inestable y si es dueña de casa su marido está en alguna de esas condiciones laborales, casada y católica, no participa en su comunidad religiosa ni percibe los cambios de la iglesia. Cree que el castigo por parte de Dios "depende" de algunos condicionantes, cree en la otra vida y la imagina como el paraíso donde van los buenos. Sin embargo, no la ve como premio sino más bien como lugar para descansar. No cree en la existencia de clases sociales y dice pertenecer a la clase media. Su fe no es asumida muy personalmente sino más bien como prevalencia de una tradición cultural a través, por ejemplo, de influencias familiares. El creyente por necesidad de creer ( $31 \%$ de la muestra), se encontraría entre las mujeres que tienen entre 21 a 30 años y que han estudiado más allá de la educación básica. Está entre los asalariados o sus esposas. Dice participar "a veces" en la comunidad religiosa y en los oficios religiosos. No está de acuerdo con los cambios de la iglesia. Tiende a no creer que será castigada por Dios si cae en pecado. Se encuentra entre quienes no creen que haya otra vida como entre quienes creen que el premio a los sufrimientos de esta vida está en esa otra vida. Prefiere educar religiosamente a sus hijos fuera de la casa. En conjunto es una persona con mayor definición de sus diversas posiciones. Su fe es producto de una cierta búsqueda de coherencia más razonada en su visión de mundo. El creyente por experiencia típico sería un hombre entre 31 y 40 años, que ha estudiado más allá de $8^{\circ}$ básico y es conviviente, es asalariado. Evangélico que dice participar en su religión y está de acuerdo con los cambios de la iglesia. Ve la otra vida como la vida eterna, pero cree que es en esta vida donde todo se paga. Prefiere dar la educación religiosa a sus hijos en la casa. Dice pertenecer a la clase obrera o trabajadora. Su fe refleja una mayor experiencia eclesial y una mayor conciencia social, es una respuesta a una experiencia religiosa personal. El creyente residual típico incluye a los más jóvenes (que quizás no han desarrollado aún una actitud propia ante la fe), a los solteros, estudiantes o cesantes. Se dice sin religión, y si la tiene participa en su comunidad religiosa. No contesta la pregunta acerca de si hace mandas habitualmente. Tiene una imagen propia de la otra vida y dice pertenecer a la clase social de los pobres.

Planteamiento de hipótesis en las conclusiones: 
El autor, más que plantear hipótesis en las conclusiones, plantea hipótesis interpretativas en relación con los resultados generales.

El hecho de que las mujeres tiendan a ser más creyentes que los hombres, se interpreta como que "mientras el hombre está generalmente sometido a condiciones de trabajo que requieren de una mayor interpretación racional, ello abonaría su receptividad a corrientes secularizantes. La mujer (...) en cambio, tendría una vida un poco más ligada a los fundamentos vitales de la existencia y estaría más ex puesta a las circunstancias adversas de marginalidad y pobreza que la llevaría a afirmar su creencia religiosa" (p. 25).

- Respecto a los 3 tipos ideales de creyentes, dice el autor que "tras estas tendencias hay diferentes grados de "exposición" a las tendencias secularizantes propias de la sociedad moderna industrial y diversos grados de incorporación a una cultura dominante en ella de carácter más racional y que da menos valor a la tradición. La creencia por tradición representaría aquellos sectores del pueblo que están menos incorporados a esta cultura. Una vez que la tradición ha sido puesta en cuestión, lo que aparece en su lugar no es la "racionalidad" típica de los medios secularizados. Lo que más parece acercarse a ellos es la creencia por necesidad: postular la necesidad de un orden en la realidad que de algún modo necesita estar avalado por una instancia trascendente... Junto a esta posibilidad aparece también la creencia por experiencia, que estaría mostrando un nuevo camino por el que el pueblo revitaliza sus tradiciones religiosas y las re-crea sobre las bases de las nuevas experiencias (...) como pueblo oprimido en la sociedad dependiente" (p. 39).

Se establecieron 3 credos, que corresponden a la articulación lógica en un símbolo de 3 tipos de creencias vigentes hoy en esta cultura popular. Para cada tipo de creyente (tradicional, por necesidad y por experiencia) se construye un credo. El credo para el creyente por experiencia se subdivide en 3 subtipos: creyente converso (evangélico), creyente por necesidad progresista y creyente católico con conciencia crítica.

\section{CONCLUSIONES}

El autor dice: “... no nos parece legítimo pretender sacar conclusiones directamente de la investigación" (p. 269). Sus conclusiones se refieren al análisis entre la investigación y la acción pastoral. A este respecto, el autor señala que "en la acción pastoral siempre están operando mediaciones de interpretación de la realidad social y cultural. La evangelización de la cultura popular exige (...) plantearse el problema de las estructuras y relaciones sociales que son el soporte material de la cultura, y más exactamente de que la cultura popular se encuentra en una situación de opresión" (pp. 270-272).

"Evangelizar a la cultura popular no significa añadir un conjunto de valores e ideas cristianas a una cultura ya existente, sino que debe poseer un carácter transformador de la cultura popular en su estado actual en un sentido liberador, 
por las múltiples opresiones que sufre el pueblo y que también reproduce en su cultura y vida cotidiana.

Surge la necesidad de revisar el proceso de formación de los agentes pastorales en sus diversas etapas y elementos desde la perspectiva de su capacitación y preparación para captar desde dentro las características de la cultura popular" (p. 275).

\section{Apreciaciones crfticas \\ ACERCA DE LOS ESTUDIOS ANALIZADOS}

El estudio de Lalive sobre el movimiento pentecostal en Chile se presenta como un trabajo serio, objetivo y de una perspectiva sociológica profunda. Maneja adecuadamente la información en relación al tema, recurriendo a diversas fuentes de datos, tanto teóricas como empíricas con el fin de realizar el estudio, el cual resulta muy completo. En un sentido crítico, el cuestionario aplicado a las 3 muestras señaladas, es un complemento no demasiado relevante dentro de su investigación. El análisis histórico resulta más útil al autor para trabajar sus hipótesis. Su obra es clarificadora para el lector y la selección de los métodos parece bastante adecuada a los propósitos de la investigación.

En el estudio acerca de la religiosidad popular chilena el autor refleja una profunda preocupación metodológica en su investigación empírica, explicando los pasos dados de manera muy detallada. El marco teórico resulta apropiado a sus objetivos. Críticamente podría aludirse al hecho de que Cruz duda de algunos resultados de su entrevista, considerando que no reflejan lo esperado. En ese aspecto queda al lector la duda acerca de por qué el autor cree en algunos resultados más que en otros, si todos ellos provienen del mismo instrumento aplicado. En general, el trabajo de Cruz es de interés aunque sus conclusiones son algo obvias, ya que busca verificar a nivel empírico, para Chile, aquello que se sabe teóricamente. El hecho de que sea una investigación de tipo amplio, que pretende abarcar una gran cantidad de entrevistados, representantes de 3 contextos diferentes, hace de este trabajo de tipo exploratorio un estudio sociologico de tipo general acerca de la religiosidad popular chilena.

La posición de A. Bentué frente a la temática en estudio es clara y precisa. Sin embargo, pese a la solidez de sus planteamientos teóricos, queda al lector la duda acerca de si las conclusiones provienen de sus datos o de sus propias convicciones, claramente vislumbradas desde el comienzo la mayoría de ellas. Otro punto crítico lo constituye el aspecto metodológico de su trabajo ya que hay poca claridad respecto a la encuesta aplicada en la población en estudio. No menciona -tal vez hasta desconoce-el criterio para seleccionar a los encuestados, aunque supone el sondeo probabilista. Su reordenamiento de datos secundarios con el fin de categorizar respuestas abiertas del instrumento original también deja lugar a dudas, ya que el lector entiende que reordenó encuestas respondidas de manera abierta con el fin de permitir el uso de porcentajes. Las modificaciones efectua- 
das sobre una encuesta aplicada por otros y respondida por una muestra de 93 personas, cuyos datos generales no son dados a conocer, plantea dudas metodológicas. Sobre todo considerando que gran parte de los resultados y conclusiones son extraídos de dicho instrumento. Otro factor crítico lo constituye la sobregeneralización de su resultados. Habría que realizar comparaciones con la religiosidad de otros medios marginales para verificar las afirmaciones de Bentué. Si bien, es posible suponer relaciones entre religiosidad y situación marginal y entre religiosidad, marginalidad y conciencia de clase, científicamente el trabajo empírico del autor merece dudas, específicamente los resultados de la encuesta. El autor posee una gran capacidad de análisis y de interpretación, la cual de pronto, sin embargo, hace dudar acerca de si sólo utiliza la encuesta para probar y reafirmar sus hipótesis. Pese a todo, su desarrollo teórico (diferenciar entre la causa y el sentido), su enfoque sociológico de la religiosidad marginal, etc. resultan de gran interés. En pocas palabras, las críticas en lo metodológico se dirigen hacia:

1. Poca claridad respecto de los encuestados y al instrumento original como asimismo a cómo reordenó las respuestas de un instrumento cuya forma de aplicación no se da a conocer en el texto.

2. Generaliza resultados de débil representatividad para la religiosidad marginal en general. Esto es delicado si, además se toma en cuenta que hay dudas incluso para la representatividad de los datos dentro de la misma población en estudio.

3. El uso de porcentajes de resultados de La Victoria, considerando el pequeño número de encuestados con el fin de comparar datos obtenidos por Cruz con una gran cantidad de personas, da lugar a dudas respecto de la validez comparativa de este método.

Por último, en la investigación del equipo de la Vicaría de la Zona Oeste se detecta con nitidez la falta de un marco teórico básico que dé un cuerpo a la investigación. Se realizó un excesivo cruce de variables, algunas de las cuales no tenían relevancia alguna. Los resultados no son del todo claros y dado el gran número de temáticas que se intentaron estudiar, la investigación aparece un tanto superficial. Esto se acentúa, como ya se dijo, por un excesivo cruzamiento de los resultados con factores de identificación diversos y por la falta de un mínimo marco de teoría que haga consistente todo el estudio en su conjunto. Metodológicamente, pretender la aprehensión de la realidad cultural de una población sólo a través de una encuesta y de sus resultados, parece insuficiente.

Sin embargo, un estudio como éste, que pretende comprender la religiosidad popular a través del conocimiento de otros factores culturales y de la misma realidad poblacional, tiene un gran valor para las disciplinas sociales y para los mismo pobladores hacia quien se dirigirá la acción pastoral con un conocimiento previo acerca de sus necesidades y motivaciones. 


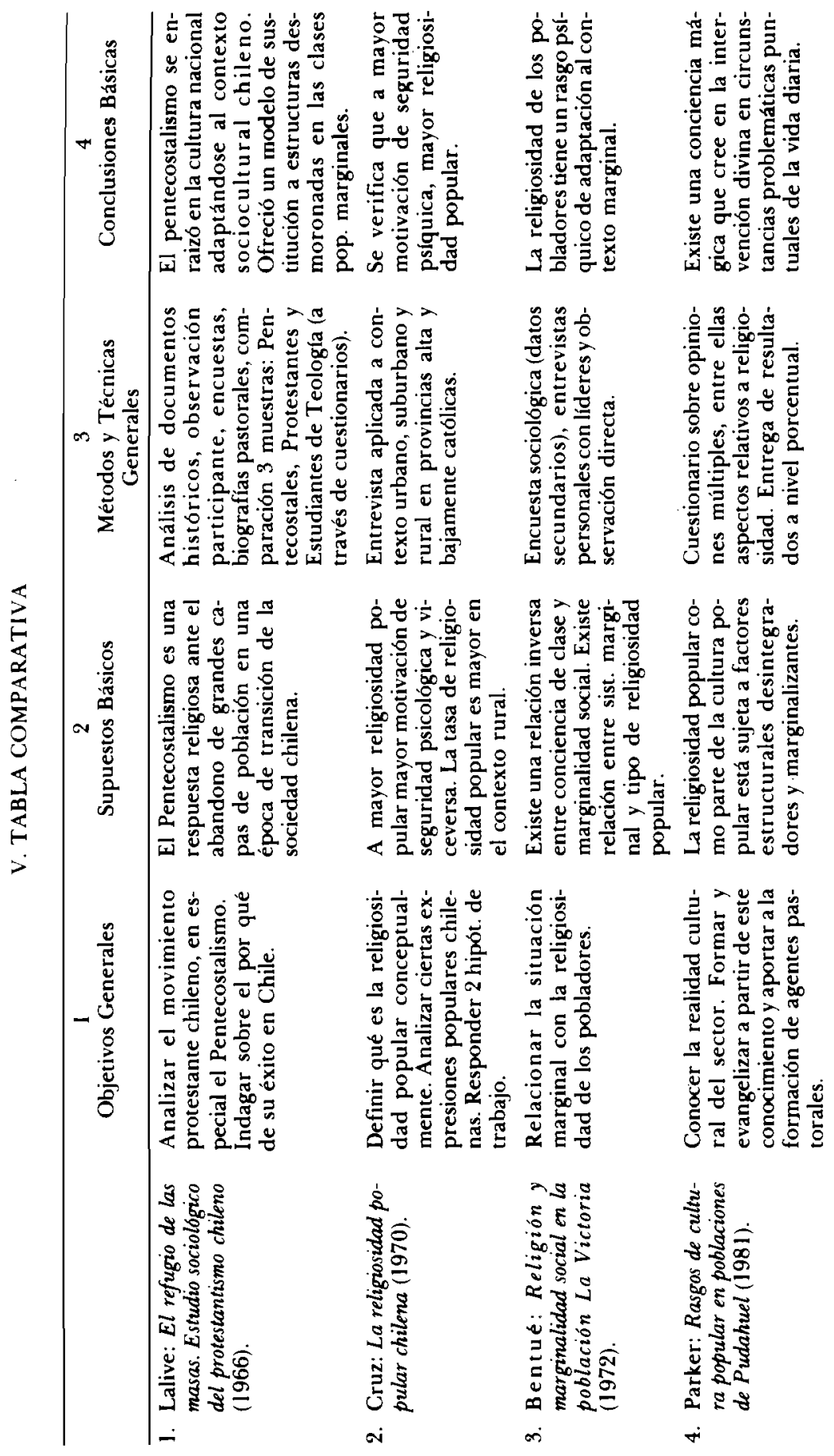




\section{Bibliograffa}

Alliende, J., "Hacia una pastoral de la religiosidad popular", en La fe de un pueblo, $\mathrm{N}^{\circ} 2$, Santiago, Ed. Mundo, 1975, pp. 101-108.

Barrios, M., "La religiosidad popular en Chile", en La fe de un pueblo, $\mathrm{N}^{\circ} 6$, Santiago, Ed. Mundo, 1977, pp. 26-40.

Bentut, A., Religión y marginalidad social: estudio socio-religioso de la Población La Victoria y reflexion teologica. Tesis de doctorado. Universidad de Estrasburgo, 1972.

Guarda, G., Los laicos en la cristianización de América, Santiago, Ed. Nueva Universidad, 1973a.

Guarda, G., "Raíces de la religiosidad popular en América española”, en La fe de un pueblo, $N^{\circ}$ 2, Santiago, Ed. Mundo, 1973b, pp. 11-17!

Jorda, M., La sabiduria de un preblo, Santiago, Ed. Mundo, 1975.

Jorda, M., El catecismo criollo, Santiago, Ed. Salesiana, 1976.

Lal1ve, C., El refugio de las masas, Santiago, Ed. del Pacífico, 1972.

N ARrol, R. et al. (eds.) Handbook of Method in Cultural Anthropology, Nueva York, Columbia University Press, 1970.

Parker, C. et al., Rasgos de la cultura popular en poblaciones de Pudahuel, Vicaría Zona Oeste Arzobispado de Santiago, Santiago, 1981.

Plath, O., Folklore religioso chileno, Santiago, Ed. Nascimento, 1966.

Prado, J.G., Santuarios y fiestas marianas en Chile, Santiago, Ediciones Paulinas, 1984.

Salinas, M., Tres dimensiones del sentido campesino de la vida, mimeografiado, 1981.

Silva, L.E., "Historia de la religiosidad popular en América Latina", en La fe de un pueblo, $N^{\circ} 6$, Santiago, Ed. Mundo, 1977.

Uribe Echevarría, Juan, Fiesta de la Virgen de la Candelaria de Copiapó: las Candelarias del Sur, Ediciones Universitarias de Valparaíso, 1978. 